\title{
Design of an interdisciplinary evaluation method for multi-scaled sustainability of computer-based projects. A work based on the Sustainable Computing Evaluation Framework (SCEF)
}

\author{
Lou Grimal \\ CREIDD, InSyTE, Université de Technologie de Troyes \\ Troyes, France \\ lou.grimal@utt.fr \\ Inès di Loreto \\ Tech-CICO, LIST3N, Université de Technologie de Troyes \\ Troyes, France
}

\begin{abstract}
This paper focuses on the evaluation of sustainability in computerbased projects. This type of evaluation has been discussed within the Sustainable Human-Computer Interaction (SHCI) community for a long time and is still considered an unresolved issue. Our paper focuses more particularly on the evaluation framework known as Sustainable Computing Evaluation Framework (SCEF). Here, we describe how such framework can be improved in several ways, and also contribute to the development of the SCEF by a better understanding and integration of sustainability dimension within computer-based projects. This main proposal is composed of three complementary contribution elements. The first contribution element concerns the categorization of socio-environmental impacts as direct, enabling and structural impacts to ensure a global view of impacts over the whole life cycle. The second contribution element concerns the enhancing of the competencies of IT managers through their engagement with the modified SCEF model. The last contribution element includes a feedback loop in the model to compare the estimation of impacts with field data.
\end{abstract}

\section{KEYWORDS}

Sustainable HCI, SHCI, framework, evaluation, validation, humansystem-nature interaction

\section{Reference Format:}

Lou Grimal, Nicolas Burger, Inès di Loreto, and Nadège Troussier. 2021. Design of an interdisciplinary evaluation method for multi-scaled sustainability of computer-based projects. A work based on the Sustainable Computing Evaluation Framework (SCEF). In LIMITS '21: Workshop on Computing within Limits, Fune 14-15, 2021.

Permission to make digital or hard copies of part or all of this work for personal or classroom use is granted without fee provided that copies are not made or distributed for profit or commercial advantage and that copies bear this notice and the full citation on the first page. Copyrights for third-party components of this work must be honored For all other uses, contact the owner/author(s).

LIMITS '21, fune 14-15, 2021,

(C) 2021 Copyright held by the owner/author(s).

\author{
Nicolas Burger \\ R\&D Department Optimistik \\ Chambéry, France \\ nicolas.burger@optimistik.fr
}

Nadège Troussier

CREIDD, InSyTE, Université de Technologie de Troyes

Troyes, France

nadege.troussier@utt.fr

\section{INTRODUCTION}

Socio-ecological stakes are more and more present in public and scientific debates, due to the urgency of the situation caused by the exceeding of planetary limits [27]. The 1950s saw a significant increase in the overall impact on the Earth system (the great acceleration). The rise of IT has accompanied this great acceleration. Computers indeed appeared around 1950 and became widely available from the 1990s. Computers have acted as an accelerator of human activities in the sense that they have enabled fast communication among people, the automation of production chains, access to data and other major society changes. Information and Communications Technologies (ICT) has thus accompanied the modernization of production lines for greater industrial performance (generally understood as an increase in the productivity of production lines). ICT produce different types of impacts (understood as negative impacts in this paragraph): environmental or social impacts. Some of those impacts are now better understood. For instance, the myth of dematerialization has long hidden the material impacts of ICT, as recently has done the myth of dematerialization through the transformation of goods into services [9].

Despite the better understanding of the ever-increasing negative impacts of ICT, the relationship between computer science and sustainability is becoming more and more important in scientific articles, to the point that the number of articles linking the two subjects has exploded in the last 5 years, passing from 249 articles in 2015 to 1120 in 20201 . Nonetheless, several questions remain: how to explain the increase of the number of papers on ICT for defined? How to model and measure ICT impacts? How to properly evaluate such models towards the achievement of sustainability goals? This last question is particularly difficult to answer. Some guiding work has been done already in this field by Remy et al. [21]. Thus, we need to develop knowledge on the evaluation of sustainability HCI to better understand the role of digital technology in the transition of society towards sustainability and be careful to not generate rebound effects [1].

Some difficulties in validating interaction tools for sustainability are due to the fact that concepts around sustainability are difficult to operationalize. For example the concept of strong sustainability 
[6] is powerful but hard to put into practice. Instead of starting from definitions, Silberman and Tomlinson [25] provide three proposal of sustainable $\mathrm{HCI}$ evaluation instead of traditional $\mathrm{HCI}$ evaluation. The three categories of tools proposed are: principles, heuristics and indices. Altogether, these tools provide data that may be useful to evaluate the sustainability to the project. However, these types of proposals do not go beyond certain problems: conflicts between the different "schools" of sustainability (weak/strong for example), the development of heuristics which focus only on certain problems and tend to over-optimize some areas with inattention to the consequences of optimization on other elements, the need to access large quantities of reliable data to construct indicators.

In this paper, we don't present a "one-fits-all" solution because we believe that the multiplicity of interactive systems couldn't be evaluated over a single method. Here, we rather explore the following ideas:

- A change in the methodology of the Sustainable Computing Evaluation Framework (SCEF) to integrate temporality and the multiplicity of stakeholders.

- A change in the SCEF on the Impact part to broader the view of the informant.

- A change in the objective of the SCEF by defining sustainability not as a goal to achieve but as a learning process.

This proposal is made in a specific context: the evaluation of computer-based projects for engineering design. Our article tends to build on previous work on validation and evaluation of computing projects and is focused on the adaptation of the Sustainable Computing Evaluation Framework (SCEF) [18]. This framework has been developed by Lundström and Pargman and was based on the "preliminary taxonomy" of Toyama [29]. Lundström and Pargman tested the taxonomy and modified it to make it "robust enough to be of direct practical use" [18]. The final model proposed by [18] is described in Figure 1. This framework has been chosen as it aims to give a method to evaluate how much a computing system can contribute to sustainability.

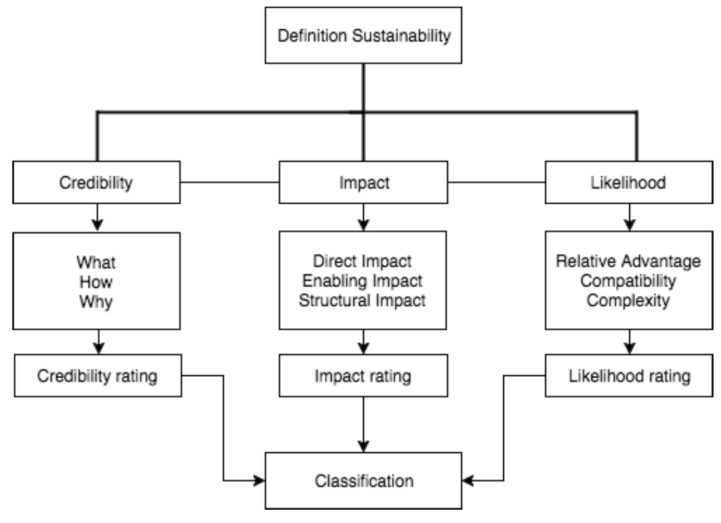

Figure 1: Sustainable Computing Evaluation Framework (SCEF)

The evaluation of a computer-based project is as it follows: the project manager must explain his intention (why the project is sustainable) to evaluate the credibility of the project. It refers to the box "Credibility" at the left of the diagram, Figure 1. Then, the project manager has to evaluate the potential impact the project on the environment and on society (direct, enabling and indirect impacts, box on the middle, Figure 1). Finally, the project manager has to evaluate how this new product / service will fit into the society (box "Likelihood" on the right of the diagram, Figure 1). Each step leads to a rate which is then integrated to a final quantitative index (aggregation).

The SCEF is relevant because it is grounded in a practical approach. The process is clear, well-defined and it has been tested on different computer-based projects. This answers the request of [22] to be more in touch with the actors and to be more grounded in the real world. The authors of the SCEF provided three conclusions:

- "Revising the definition of sustainability that is used in the SCEF into make it more tractable for computing projects." We try to answer this issue by providing a first level of validation with the framework of competences.

- "Add a quantitative aspect to the assessment process and/or consider how this can be combined with a qualitative approach." We question this conclusion by emphasizing on the qualitative level of the framework and by deemphasizing on the quantitative part.

- "Elaborate on the Credibility dimension and consider how the scope of a computing project (in space and time) affects the assessment and how this can be integrated into the evaluation process". We try to answer this issue by defining the role of direct and indirect stakeholders in the framework.

Our article is composed of 3 parts. The first part is a discussion on the SCEF model with a focus on (1) the impact category, and (2) the usefulness of a model regarding competencies which can be acquired. The second part is a description of the contribution element for the impact section and a suggestion on the integration of temporality and field data via stakeholders. A third part will be dedicated to a discussion on the contribution element and to give leads to potential future works.

\section{DISCUSSION ON THE SCEF}

SCEF uses several other frameworks such as Hilty's categorization of impacts in direct, enabling and structural impacts [14]. The first part of this section focuses on these impacts by enlarging their use in the model, introducing the phases of a project: beginning, middle and end of life. SCEF results in numerical scores to estimate the sustainability of a project. We are discussing the need of these scores by introducing a competencies approach. Thus, this section is linked to the first contribution element of this paper as it deals with categorization of socio-environmental impacts into direct, enabling and structural impacts and with the second contribution element of this paper as we introduce the notion of competence to transform IT project managers by their acquisition of engineering competences for sustainability.

\subsection{Impact category}

The categorization in 3 orders of impacts (direct, enabling, structural) taken from the literature (Berkhout [5], and Hilty [14]) and used in the "Impact" category is commented in this section. This 
section is directly related to the first contribution element. Figure 2 represents the structuration in 3 levels described by Hilty [14]:

- Direct effects are effects directly linked to the materiality of ICT

- Enabling effects are effects linked to the use of ICT (industrial production and indirect environmental impacts)

- Systemic effects (structural impacts in the SCEF) are effects on structural aspects of society ("everyday life, economic structures and lifestyles" [15])

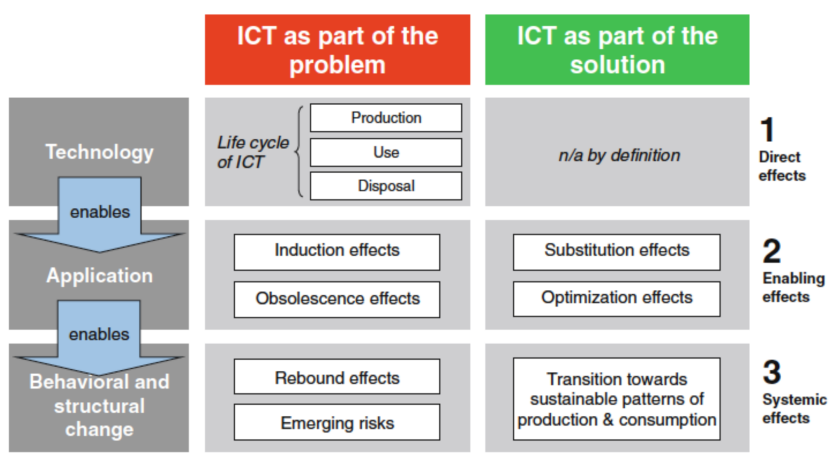

Figure 2: Matrix of ICT effects, based on [13] and taken from [14]

This categorization has the drawback of not allowing to see all the impacts of information systems on human organizations over their entire product life cycle. Indeed, the impacts on human organizations are concentrated on the use phase (enabling impact). However, the early life phases (extraction of raw materials such as lead or arsenic for the electronic parts production of a smartphone) have strong and long-term impacts on human societies, for example for communities who live close to mining activities [4]. This aspect is not mentioned in Berkhout's paper [5] and only one sentence can be found in Hilty and Aebisher's paper [14] "In some cases, it may be necessary to include an assessment of social impacts, for example the social impact of the mining activities required to produce the raw materials, or the social impact of informal recycling." We believe that an assessment of social impacts is not the only way to make sure social impacts of ICT production are visible.

To illustrate this point, we make a short focus on the example of lithium, a material coming mainly from South America, more precisely from Chile (38\% of the world's reserves) [17]. The extraction of lithium in the areas has dramatic consequences on the environment ("the fast expansion of lithium mining operations in the ASF is found to have a strong correlation with the ongoing environmental degradation in the study area" [17]) and on individuals. The social impact of ICT production doesn't appear in Berkhout's paper whereas it is a major effect on humans' organizations. Indeed, social conflicts has emerged because of environmental impacts of mining activities and can destabilize some communities [2]. How are these elements taken into account in the model of direct, enabling and structural impacts? Also, more than social impacts, health related impacts, political and geopolitical issues need to be explained to understand local mining situations. There we found some indirect and structural impacts of ICT coming from those direct effects, nevertheless, it seems that those related impacts don't appear in the categorization.

Figure 3 shows in yellow what is taken into account in ICT's impact categories, and in grey, the categories of impacts which are poorly taken into account. The structural and enabling impacts coming from the beginning of life and end of life are quite important to have a holistic view of ICT impacts. Also, the enabling impact for the middle of life is shown as "partially taken into account" because those enabling impacts can be viewed from a very optimistic or pessimistic perspective depending on the person who establishes them. Indeed, "enabling impacts" show what ICTs can do but not what they can actually produce in the practice. An example taken from Svane [28] is given by [23] : "smart energy saving devices in apartment buildings in Swedish housing area Hammarby Sjöstad were often not used as intended, resulting in a situation where "interactive ICT in smart infrastructure enables energy efficiency but does not provide it" ". It is therefore important to be very attentive to this category of potential impacts so that they are not an excuse for designing impactful technologies. Another example is given in [19] with OLED screens. Those two examples shows that technological "solutions" are not sufficient to reduce energy consumption of ICT and that habits of end-users or the whole ecosystem regarding the use of digital tools need to be rethink. Thus, there may be a gap between the desired (and even potential) effects and the actual effects. The two should not be confused, otherwise some technologies may be classified as sustainable when they are only potentially sustainable. So, if some technologies are only potentially sustainable through design, is it possible to consider this potentiality into an evaluation?

Moreover, the distinction between the positive and negative impacts of ICT's obliges the designer to give his culturally oriented point of view (positive or negative) on an element. For example, whereas some phenomena at the micro-level seem to be positive from a perspective of intensive production (from the designer point of view), they have negative consequences from a socio-ecological perspective on meso and macro-levels - consequences that may be neglected (unintentionally or not) from the first perspective. For instance, optimization is positioned in positive part in Hilty's proposal, but optimization positioned in a context where economic profit is sought would lead this optimization to eventually increase the impacts of the product. This phenomenon, known as the rebound effect, is positioned in the negative part in the structural impacts. Figure 3: Considered impacts related to the ICT life phases in Hilty's proposal

So how can optimization be categorized as positive while it leads to structural negative dynamics and non-behavioral change? At least, the links between direct, enabling and structural impacts should be defined (graphically) to not lead to misunderstandings.

ICT impacts are complex and dividing them into positive and negative impacts without defining the period observed, and the socio-economical context of those impacts, seems superficial.

To sum it up, the categorization of ICT's impacts between direct, enabling, and structural impacts needs to address a wider scope than environmental impacts only in order to give a holistic view of the consequences of ICT production. Also, enabling impacts are often more potential impacts, thus a method to not overestimate 
them should be implemented. Such a method is discussed in section 3 of this paper, considering feedback loops and temporality.

Also, authors Lundström and Pargman explain: "When asked about the impact or effect of their projects, the informants did not differentiate between direct, enabling or structural impact, and most were concerned mainly with enabling impact". It shows how informants are believing in the goal their computer-based project is supposed to achieve rather than real impacts. Our proposal is to provide informants data on the different types of impacts (direct, enabling, structural at different life cycle stages). Thus, the information with which they fill in the impact structuration model do not come from their beliefs but from scientific knowledges and field data.

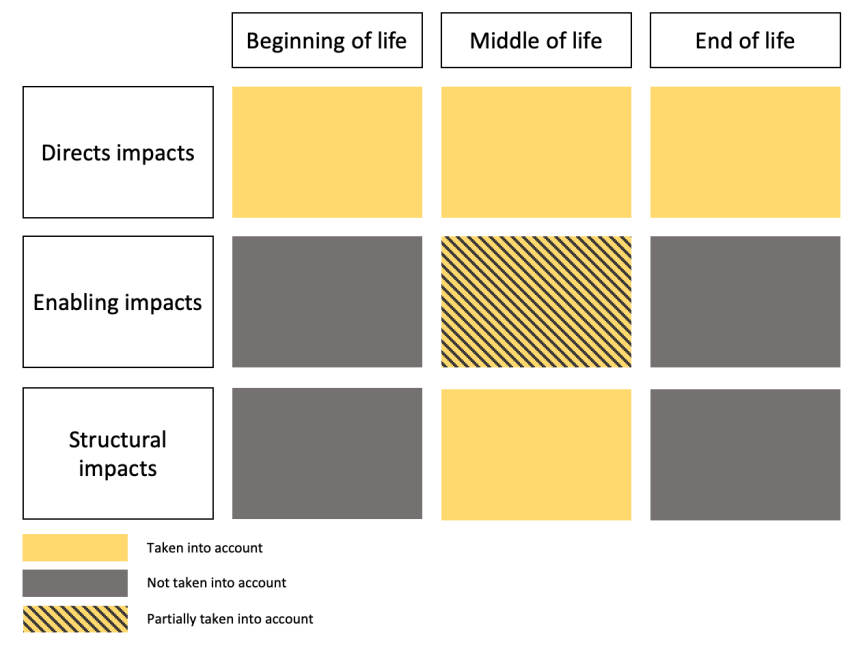

Figure 3: Considered impacts related to the ICT life phases in Hilty's proposal

We are suggesting that the representation of impacts in Figure 3 should prevail in the "Impact" part of the SCEF model to help the stakeholders of a project to better understand direct, enabling and structural impacts during the overall life cycle of the computerbased project proposed, and act accordingly.

\subsection{Do we need models?}

To contest the need of scores presented in the initial SCEF, we introduce the competencies approach in three parts. Firstly, we explain why we question the use of scores. Secondly, we explore why competencies can be relevant for the SCEF. Thirdly, we match the SCEF to the suggested competencies framework. This section is directly related to the second contribution element of this paper.

2.2.1 Modeling and final results. We are adding one comment from Lundström and Pargman [18] themselves: "It should also be kept in mind that creating a framework is only a proximal goal where the ultimate goal is to achieve a sustainable society". It seems important to us to support this point. How can this framework be relevant for the sustainable transition? The design of validation methods for interaction tools must also take into account the capacity of these tools to evolve over time and to have an impact on the dominant socio-technical regime (to disrupt it) [11]. In the evaluation model of a computing system proposed by Lundström and Pargman, the evaluation is defined by a final score. This score gives the level of sustainability of the analyzed product. But this rating is not multicriteria, so what does this final score means? This framework helps to have a clear overview of the total impacts of a system. So, we ask ourselves whether the relevance of the model lies more in the realization of the model than in the final score obtained.

Taking the Life-Cycle Analysis (LCA) method as an example, this question is asked in the LCA community with the technique of normalization being debated (subject of the 72nd Forum « Normalization and weighting. The forgotten theme in LCA ») [24]. The interest of LCA is in its multi-criteria output and its method, so normalization is a way to simplify complex results and should not be done without precautionary measures. Normalization can hide the complexity of the final results. Also, the level of sustainability of a given system can be different at short or at long term.

Is it really possible to compare products with a single score reflecting a multitude of environmental and social impacts? What can we say after obtaining this final score? Regarding this issue, we suggest that the relevance of the model is not in this final score but on the intellectual process it obliges stakeholders to pass through. The ability for stakeholders to take this approach in their own hands will depend on the competencies they have in many fields competencies better used in interdisciplinary contexts.

2.2.2 Competence-based approach. Choices made while designing the product, with integration of the different life-cycle phases of the product, directly influence the impacts of this product. Thus, the sustainability of a product (or project) lies on the way it is designed. Then the question of the competencies of the designers arises. We are focusing on the changes in the knowledge and competences acquired by stakeholders (project owners mainly) in contact with the validation frameworks. It allows us to get out of the debate of a quantitative rate (index) to not overpass (previous section). If the project owner has a reflexion on the way the digital tool is designed then potentially, project leaders have or will acquire these competencies in design for sustainability (to better design their product).

This proposal opens evaluation perspectives that focus not on the object as such but on the competencies of the designers which are required for the design for sustainability. We believe that SCEF, by the questions on credibility, the description of the different impacts, and the prospective exercise on likelihood can bring substantial competencies. One of the main frameworks from the literature is the one of Quelhas [20].

The eight competencies around sustainability are the following: 1 critical thinking (challenge the status quo), 2 working in an interdisciplinary group (develop empathy), 3 ability to solve problems (apply engineering design for wellbeing and sustainability), 4 systemic thinking ("ability to identify and understand interactions between systems and people"), 5 normative competence ("ability to understand and reflect on the standards and values that ground people's actions"), 6 self-knowledge ("ability to reflect on one's own role in the local community and society"), 7 contextualization and vision of the future, 8 strategic competence ("ability to understand and evaluate several futures"). 
Design of an interdisciplinary evaluation method for multi-scaled sustainability of computer-based projects. A work based on the Sustainable Computing Evaluation Framework (SCEF)

A link between these competencies and the SCEF can now be done.

2.2.3 Learning through models. Each part of the model can be related to several competencies, as seen in the Figure 4. Also, as the persons who fill in the model are also designing the system (main stakeholders of the project), there are also supposed to develop two competencies: the ability to solve problems and the ability to work in an interdisciplinary group.

Credibility section of SCEF is about expressing the beliefs of the project owner. This section questions the project owner on the impacts he wants to have on society so his role in the sustainable transition of society (6 self-knowledge). Critical thinking (1) can be expressed because thanks to the project (how it is done), it should challenge the status quo (to get back an example from the authors [6], HardwareLabel wants to have an impact on standards and thus in the long term on practices). Strategic competence (8) can be identified in the "how", when the informant is in need to describe the value chain and define how the proposed product can lead to new challenges, new opportunities and answer structural problems regarding sustainability.

Impact section is about describing the different impacts of the computer-based project in order to have a holistic view of its consequences. Obviously, the systemic thinking (4) competencies of the informants will be developed. Critical thinking (1) can be developed in this section as the learning of some types of consequences can bring the informants to reflect on the project's intention regarding harmful impacts. Normative competencies (5) can be developed through the understanding of structural impacts (norms, values that are involved in structural changes).

The "Likelihood" section is about the probability for a project to provide changes in society. Thus, the limitations have to be defined (habits, values, law, etc). As contextualization (7) "involves an engineer sensitivity to understand why certain knowledges and abilities are necessary to visualize solutions and consequences in a broader context", it can be used to understand the answers that can be given to those limitations. Also "Vision of the future" is about evaluating several potential futures, which is the given exercise of this section. An analysis of the current values and perceptions need to be done, allowing to develop critical thinking (1) and understanding how the computer-based project is going to disrupt them. Finally, this prediction of problems in all the potential dimensions can also contribute to develop systemic thinking (4).

The opportunity to develop all those competencies by working on the 3 sections allows us to state that this model can help informants to reflect on the efficiency of their projects (comparing their intention, impacts and potential barriers) and may enable the re-consideration of some aspects of their projects.

Reasoning on the competencies level and not on a project level opens this model to larger scales since competencies accumulate over time and allow stakeholders to make decisions with more and more background for future projects. Having developed those 8 competencies does not mean we can conclude that the developed socio-technical system is sustainable. It rather shows that the stakeholders state of mind regarding their project may change over time after learning new competencies. New design ideas can emerge.

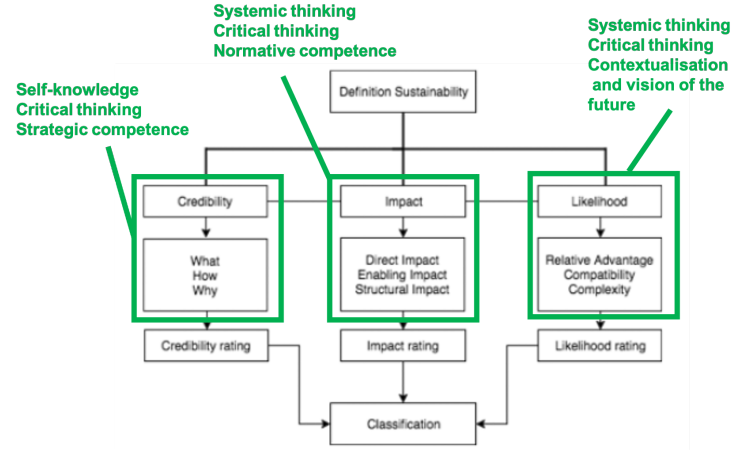

By the project itslef : ability to solve problems and working in an interdisciplinary group (collaboration)

Figure 4: Links between the competencies of Quelhas and the SCEF model

In the next part and more precisely on Figure 5, a feedback loop is introduced to take the SCEF model a step further into a more holistic approach. How sustainable the product is at the end of this first step of design will depend on the quality of the reflection during these phases and on the data used to make the decision. In the next part, we focus on the improvement of Hilty's model (to fix the issues mentioned previously in part 2.1), with regards to Quelhas competencies that have been matched to the SCEF categories.

\section{PROPOSAL}

This section is divided into two parts: (1) an example of the proposed structuration and (2) changes in the use of the model to develop interdisciplinary work, and a proposal for the assessment of enabling impacts.

Moreover, this section is used to explore which competences are developed by the designer. Thus, the link between competencies from Quelhas and the updated SCEF are highlighted.

The first subsection (3.1 Impact) contributes to the first contribution element of this paper whereas the second subsection (3.2 Enabling impacts and interdisciplinarity) contributes to the third contribution element of this paper. Both subsections are linked to the second contribution element as they improve the competences learned by engineers involved in IT management projects.

\subsection{Impact}

We previously mentioned that the structuration of the impacts did not allow the informants to see all the interaction types in the digital system. Thus, a proposal was made to develop the enabling and structural impacts of the beginning and end of life of the studied system. In this section, we are going to put into practice a short example of impacts, focusing only on the beginning of life of a smartphone, and more precisely focusing on one material used for the production of smartphone: cobalt $(\mathrm{Co})$. The focus is made on the extraction activity of cobalt mining in the Democratic Republic of Congo (DRC) [8], [26], which have local enabling and structural impacts (Table 1 ).

While filling in Table 1, we noticed that the distinction between enabling and structural impacts according to Hilty's can be discussed. We decided to take the following logic: 
- Enabling impacts will have discrete outcomes (mathematically speaking) in the sense that an enabling impact will allow a person to act differently (in his life, job, practices...) when interacting directly or indirectly with the analyzed project.

- Structural impacts will have continuous outcomes, changing the behavior of individuals after the project has been deployed, even if not in direct or indirect interaction with the project.

Lastly, before diving in the example, it is important to understand that the goal is not to define what is positive or negative in those impacts but to describe them properly. Defining what is positive or negative will depend on the ideology, political view, and objectives of the person who reads it.

By this short and non-exhaustive list of direct, enabling and structural effects on the beginning of life of cobalt extraction in $\mathrm{DRC}$, we can see that this phase is far from negligeable from the enabling and structing effects point of view. That is why the current proposal offers a more holistic approach to take these impacts into account.

One particular benefit of this structuration is the ability to link direct impacts of ICT to structural problems of society. Such problems are usually addressed in the political life of the territory (locally from the county regulation our globally from the state regulation) and that raises the question of the depoliticizing of mainstream environmental research [16]. This structuration tends to be as much objective as possible, based on literature reviews and field data. By addressing the multi-scales impact, we are highlighting the relationship between mining activities and socio-political issues (geopolitics, armed conflicts and organization of social groups).

The development of this new categorization of impacts can help designers to understand the multi-scale impact of sociotechnical systems. In order to follow up the project, product owners must develop systemic thinking 4, critical thinking 1 and normative competence 5 .

\subsection{Enabling impacts and interdisciplinarity}

Aspects related to interdisciplinarity can easily be set aside when a project leader designs a product without dealing with the stakeholders of the tool (direct and indirect stakeholders). Moreover, enabling impacts can be added by the project leader with potentially a lot of optimism. Thus, to ensure the interdisciplinary contribution of the product (described in the Quelhas model - competence 2 - in order to be able to design a sustainable product) and its adequacy with field expectations in terms of sustainability, a proposal is made in Figure 5.

In Figure 5, we can observe the following process: the project goes through the SCEF mode. One intermediate output comes out of this model: the description of the impacts, the projection of the project into lifestyles and the legal, cultural, and technological barriers that would limit the use of the tool (Testing phase). This testing phase can be divided into smaller units of different nature $\mathrm{A}, \mathrm{B}$ and $\mathrm{C}$ in the diagram - which could refer to environmental and socio-economic data of different time horizons (in the sense of the definition of sustainability in [14]).

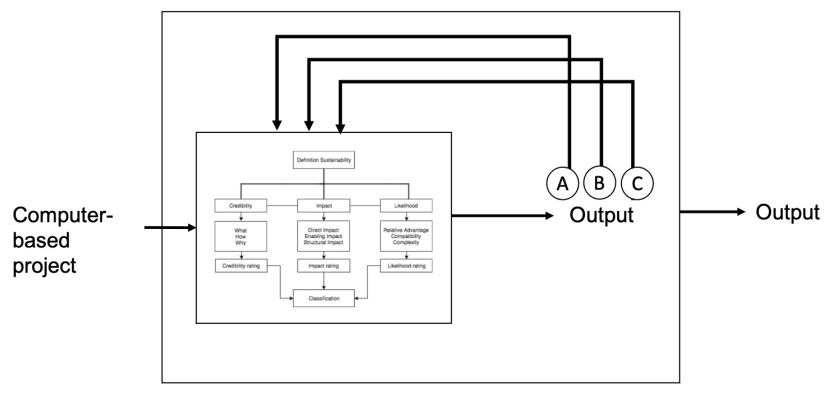

Figure 5: SCEF model improved with feedback from various field data

These elements will be tested, and stakeholders (field players, manufacturers, end-users) will be able to provide information on the project. Thus, the enabling impacts will have to be compared with field data to adjust its valuation from a possible optimistic (or pessimistic) point of view of the product owner.

The quality of this feedback loop will depend on the quality of the data from the model, but it will also depend on the quality, interdisciplinarity and diversity of actors providing feedbacks and field data on the impacts experienced by the product.

This loop can be done several times before a final output where a sustainable goal is achieved - or not. The final output is an ideal sustainable product. Reality is rarely ideal, and we see this model as a never-ending loop increasing indefinitely the sustainability of the product as it follows new discoveries in all of its aspects: (technical discovery, health problems detection, environment reaction, individual's appropriation over time, new competitors...).

For the product designer to follow up this loop, he must be anchored in an interdisciplinary team with competences in the field of sustainability. At least, the ability to work in an interdisciplinary context is needed 2 . Therefore, competencies are important to be considered and managed appropriately alongside the project to improve the quality of the final output.

\section{DISCUSSION}

The following three improvements have been made on SCEF:

- Focus on interdisciplinarity and competencies. SCEF numerical ratings are necessary but are not at the heart of our new evaluation process. In fact, the description and understanding of the links between the stages of a product's life cycle and the multi-scale and temporal consequences generated, as well as the linking of stakeholders throughout the life cycle, offer a particularly complete impact picture to the designer/project owner. This form of socio-ecological assessment allows the designer to get away from the problem of access to data from the start and helps to improve its view on the product, prototype after prototype, and version after version.

- Distinguish direct, enabling and structural impacts in SCEF. This allows the informant of the model to have a more global and coherent view of its project.

- Introduce feedback with field data. These feedbacks mitigate the risk of over-optimism on enabling impacts. A big gap 
Design of an interdisciplinary evaluation method for multi-scaled sustainability of computer-based projects. A work based on the Sustainable Computing Evaluation Framework (SCEF)

Table 1: Focus on cobalt extraction's impacts (fabrication process for smartphones' production)

\begin{tabular}{|c|c|}
\hline Impact & Beginning of life of a smartphone (focus on cobalt) \\
\hline Direct & Environmental issues \\
\hline impacts & $\begin{array}{l}\text { Cobalt extraction leads to some local environmental issues. Here is a non-exhaustive list: eutroph- } \\
\text { ication [26], ozone depletion due to the burning of diesel for machines [7], land use and thus } \\
\text { biodiversity loss, deforestation, soil erosion [26]. }\end{array}$ \\
\hline- & Working conditions \\
\hline- & $\begin{array}{l}\text { Small-scale mining practices are leading to dangerous working conditions. Indeed, workers are so } \\
\text { poor that they cannot afford ladders and do not have suitable protection [26]. }\end{array}$ \\
\hline - & Health problems \\
\hline - & $\begin{array}{l}\text { Health problems increased in the workers population (cancer effect) [7]. Those health problems } \\
\text { are not limited to the workers. Indeed, all the local population are contaminated by toxic hazards } \\
{[26],[3] \text {. }}\end{array}$ \\
\hline Enabling & High-tech industry \\
\hline impacts & $\begin{array}{l}\text { Cobalt extraction allows the production of electronics components, like batteries for the electric } \\
\text { car industry (half of the cobalt extracted today is destined for batteries [10]) which help reducing } \\
\text { carbon emission in the transportation sector. }\end{array}$ \\
\hline - & Economic improvement \\
\hline - & $\begin{array}{l}\text { Development of the mining sector in RDC leads to small-scale and artisanal miners, and large- } \\
\text { scale industrial mining [30]. This can lead to enabling impacts in those localities (linked to cobalt } \\
\text { extraction): "The cobalt mining boom has been key in the DRC to jobs and escaping poverty, } \\
\text { creating a new middle class. Responsible mining has built schools and hospitals that would not } \\
\text { otherwise be there, reaching thousands of people, and it has promoted the much needed image } \\
\text { abroad that the DRC is safer for foreign investment." said an expert interviewed in [26]. The same } \\
\text { authors present some benefits from cobalt mining which can be considered as enabling impacts } \\
\text { issued from direct mineral extractions: "poverty reduction, community development, regional } \\
\text { stability, ancillary markets". }\end{array}$ \\
\hline Structural & Corruption, violence and armed conflicts \\
\hline impacts & $\begin{array}{l}\text { Some serious challenges emerged around cobalt extraction: "six serious challenges: accidents and } \\
\text { occupational hazards, environmental pollution and degraded community health, exploitation of } \\
\text { miners and unfair market practices, the erosion of democracy via corruption and malfeasance, } \\
\text { displacement of indigenous peoples, and violent conflict and death." [26]. }\end{array}$ \\
\hline- & $\begin{array}{l}\text { The valuable resources in DRC (cobalt included) lead to armed conflicts between individual groups } \\
\text { seeking profits or influence in the region. These profits and influence are directly connected to the } \\
\text { economy's dependence of cobalt in the area [16]. }\end{array}$ \\
\hline - & Foreign investments \\
\hline - & $\begin{array}{l}\text { As seen before, mining sector has bring to the state some revenues [26]. In the last } 20 \text { years, } \\
\text { privatization of mining industry allowed foreign companies to invest in the country. }\end{array}$ \\
\hline - & Price instability \\
\hline- & Cobalt prices are very volatile, and miners well-being is directly dependent on its fluctuation [26]. \\
\hline
\end{tabular}

between the fields data and the estimated enabling impacts may reveal gap in the designer's understanding and introduce deeper changes in the product or a change of goals. It is important to note that the potential diversity of data justifies even more the use of interdisciplinarity work regarding the sustainability of a project.

Subsection 4.1 gives some indication on how to implement a competencies approach with several actors forming an interdisciplinary team with the project owners. We then discuss the limitations and future works in subsection 4.2 to anticipate abuses or misuses of the updated framework.

\subsection{Impacts' representation and competencies}

The competencies for sustainability in engineering proposed by Quelhas allow us to evaluate the impacts of an IT project while observing the changes of competencies of the informants.

The fact that the project owners are the people who fill in the model, leads to biases in filling in the different sections (credibility, impact, livelihood). However, these biases can be mitigated by the other stakeholders (field players, manufacturers, end-users) contributions. Those stakeholders bring different perspectives on the project and allow the construction of a global vision of the impacts.

These feedbacks could lead to disruptive changes of the product, in the whole value chain; changes that must be evaluated again. Therefore, we propose to add this loop shown 
on Figure 5 Showing the whole value chain and its structural impacts on a local scale allows the designer to realize its multiscalar impacts. Moreover, the differences shown by these feedbacks between the external world (from the designer perspective), the interpreted world and the expected world can have an impact on the designer's willingness to act in that world and therefore to design his project [12]. These feedbacks could thereby influence the other parts of the SCEF, namely the credibility and likelihood of the project.

Thus, the relevance of SCEF is, firstly, to start from the intentions of the project actors. Secondly, it allows to consider technical aspects of the project (impacts on the life cycle and projection of the tool in use). Finally, feedbacks from the field allow a comparison between the beliefs expressed (intention, livelihood) and the observed impacts (impacts). The adequacy (or not) between these beliefs and the impacts can be observed and can also be a subject for discussion with the informants for support and potential changes in the initial project.

\subsection{Limitations and future works}

It seems that this updated model is relevant both for the evaluation of disruptive projects to know their "level" of sustainability, but also to accompany project leaders (stakeholders in general) for a change in their way of thinking and conceiving the technology. Our work is a form of evaluation and coaching on socio-ecological issues that should be tested in practice.

Temporality between feedbacks becomes a key parameter whose influence needs to be further analyzed. Indeed, if a feedback is given shortly after the first prototype of a project, it can miss long term effects. On the opposite, if a feedback is taking too long before deciding (releasing the project or not depending on the feedback data), it may give an already outdated project or it may worry investors. The question of time is a recurrent issue in the evaluation of the SHCI community's work. This question may even call into interrogation the feasibility of the evaluation given the cost (human, economic) that it requires. This limitation has already been discussed by Remy in [22].

Moreover, following feedbacks of a testing phase, big changes may need to be done on the project, which may take time. The deployment of a new version of the project may also take time. These durations need to be considered in the model to give more control to the designer. On the contrary, if these timings are not considered, the model can introduce biases when the project manager neglects (voluntarily or not) the long-term effects.

Validating this model can be difficult. Conducting two parallel projects with the original SCEF and this proposed model would need to have two identical teams working on the same project, which seems very unlikely to happen (regarding time, money and how to have identical people on both projects). Instead, comparing the narrative feedbacks from stakeholders to demonstrate that there is a wider range of impacts to be considered with the improved SCEF model on one project, to another with the traditional SCEF model could be a good starting point. Moreover, the work of Remy et al [21] proposes some methods to evaluate the sustainability of $\mathrm{HCI}$ and can be of use in a dedicated future work focusing on the validation of modified SCEF.
The paper's proposal concerns only computer-based projects developed by engineers because the added brick has been thought in this scope. An interesting approach would be to see if this model could be adapted to engineering projects in general instead of IT projects only. We don't know yet how our proposal can be generalized to other systems.

Finally, our proposal doesn't address issues related to ideological beliefs. Indeed, even if decision makers have a holistic view of socio-ecological dramatic impacts, the final decision can privilege economic profits over environmental and/or social sustainability. This issue can be explored to better understand this type of deadlock (ideological clashes between stakeholders) in future works.

\section{ACKNOWLEDGMENTS}

All the authors would like to thank the authors of the SCEF model for their contribution, which has been a fundamental basis for this paper.

We thank Santiago Perez for proofreading and correcting the English version of our article. We also want to thank the reviewers for their concrete and helpful comments which allowed us to improve the paper.

We want to note that "ACVnum: Life Cycle Assessment and Digital Transition" is co-financed by the European Union. Europe is committed to Champagne-Ardenne with the FEDER/FSE/IEJ Champagne Ardenne Operational Programme 2014-2020 / European Regional Development Fund.

\section{REFERENCES}

[1] Blake Alcott. 2005. Jevons' paradox. Ecological Economics 54, 1 (July 2005), 9-21. https://doi.org/10.1016/j.ecolecon.2005.03.020

[2] Sally Babidge and Paola Bolados. 2018. Neoextractivism and Indigenous Water Ritual in Salar de Atacama, Chile - Sally Babidge, Paola Bolados. https://journals. sagepub.com/doi/10.1177/0094582X18782673

[3] Célestin Banza Lubaba Nkulu, Lidia Casas, Vincent Haufroid, Thierry De Putter, Nelly D. Saenen, Tony Kayembe-Kitenge, Paul Musa Obadia, Daniel Kyanika Wa Mukoma, Jean-Marie Lunda Ilunga, Tim S. Nawrot, Oscar Luboya Numbi, Erik Smolders, and Benoit Nemery. 2018. Sustainability of artisanal mining of cobalt in DR Congo. Nature Sustainability 1, 9 (Sept. 2018), 495-504. https: //doi.org/10.1038/s41893-018-0139-4 Number: 9 Publisher: Nature Publishing Group.

[4] Flavia L. Barbieri, Jacques Gardon, María Ruiz-Castell, Pamela Paco V, Rebecca Muckelbauer, Corinne Casiot, Rémi Freydier, Jean-Louis Duprey, Chih-Mei Chen, Jacqueline Müller-Nordhorn, and Thomas Keil. 2016. Toxic trace elements in maternal and cord blood and social determinants in a Bolivian mining city. International fournal of Environmental Health Research 26, 2 (March 2016), 158174. https://doi.org/10.1080/09603123.2015.1061114 Publisher: Taylor \& Francis _eprint: https://doi.org/10.1080/09603123.2015.1061114.

[5] Frans Berkhout and Julia Hertin. 2004. De-materialising and re-materialising: digital technologies and the environment. Futures 36, 8 (Oct. 2004), 903-920. https://doi.org/10.1016/j.futures.2004.01.003

[6] Simon Dietz and Eric Neumayer. 2007. Weak and strong sustainability in the SEEA: Concepts and measurement. Ecological Economics 61, 4 (March 2007), 617-626. https://doi.org/10.1016/j.ecolecon.2006.09.007

[7] Shahjadi Hisan Farjana, Nazmul Huda, and M. A. Parvez Mahmud. 2019. Life cycle assessment of cobalt extraction process. Fournal of Sustainable Mining 18, 3 (Aug. 2019), 150-161. https://doi.org/10.1016/j.jsm.2019.03.002

[8] K G Fisher. 2011. COBALT PROCESSING DEVELOPMENTS. (2011), 22

[9] Blair Fix. 2019. Dematerialization Through Services: Evaluating the Evidence. BioPhysical Economics and Resource Quality 4, 2 (March 2019), 6. https://doi.org/ 10.1007/s41247-019-0054-y

[10] Xinkai Fu, Danielle N. Beatty, Gabrielle G. Gaustad, Gerbrand Ceder, Richard Roth, Randolph E. Kirchain, Michele Bustamante, Callie Babbitt, and Elsa A. Olivetti. 2020. Perspectives on Cobalt Supply through 2030 in the Face of Changing Demand. Environmental Science \& Technology 54, 5 (March 2020), 2985-2993. https://doi.org/10.1021/acs.est.9b04975

[11] Frank W. Geels. 2002. Technological transitions as evolutionary reconfiguration processes: a multi-level perspective and a case-study. Research Policy 31, 8 (Dec. 
2002), 1257-1274. https://doi.org/10.1016/S0048-7333(02)00062-8

[12] John S. Gero and Udo Kannengiesser. 2004. The situated function-behaviour-structure framework. Design Studies 25, 4 (July 2004), 373-391. https://doi.org/10.1016/j.destud.2003.10.010

[13] Lorenz M. Hilty. 2008. Information Technology and Sustainability: Essays on the Relationship between Information Technology and Sustainable Development. https://books.google.fr/books/about/Information_Technology_and_ Sustainabilit.html?id=2vlVVfFS_2YC\&redir_esc $=y$

[14] Lorenz M. Hilty and Bernard Aebischer. 2015. ICT for Sustainability: An Emerging Research Field. In ICT Innovations for Sustainability (Advances in Intelligent Systems and Computing), Lorenz M. Hilty and Bernard Aebischer (Eds.). Springer International Publishing, Cham, 3-36. https://doi.org/10.1007/978-3-319-092287 1 1

[15] Lorenz M. Hilty and Magda David Hercheui. 2010. ICT and Sustainable Development. In What Kind of Information Society? Governance, Virtuality, Surveillance, Sustainability, Resilience (IFIP Advances in Information and Communication Technology), Jacques Berleur, Magda David Hercheui, and Lorenz M. Hilty (Eds.) Springer, Berlin, Heidelberg, 227-235. https://doi.org/10.1007/978-3-642-154799_22

[16] Philippe Le Billon. 2001. The political ecology of war: natural resources and armed conflicts. Political Geography 20, 5 (June 2001), 561-584. https://doi.org/ 10.1016/S0962-6298(01)00015-4 Publisher: Pergamon.

[17] Wenjuan Liu, Datu B. Agusdinata, and Soe W. Myint. 2019. Spatiotemporal patterns of lithium mining and environmental degradation in the Atacama Salt Flat, Chile. International fournal of Applied Earth Observation and Geoinformation 80 (Aug. 2019), 145-156. https://doi.org/10.1016/j.jag.2019.04.016

[18] Anton Lundström and Daniel Pargman. 2017. Developing a Framework for Evaluating the Sustainability of Computing Projects. In Proceedings of the 2017 Workshop on Computing Within Limits (LIMITS '17). Association for Computing Machinery, New York, NY, USA, 111-117. https://doi.org/10.1145/3080556.3080562

[19] Daniel Pargman, Edvard Ahlsen, and Cecilia Engelbert. 2016. Designing for sustainability: Breakthrough or suboptimisation? (2016). https://doi.org/10.2991/ ict4s-16.2016.7 Publisher: 'Atlantis Press'.

[20] Osvaldo Luiz Gonçalves Quelhas, Gilson Brito Alves Lima, Nicholas Van-Erven Ludolf, Marcelo Jasmim Meiriño, Chrystyane Abreu, Rosley Anholon, Julio Vieira Neto, and Leandro Silva Goulart Rodrigues. 2019. Engineering education and the development of competencies for sustainability. International Journal of Sustainability in Higher Education 20, 4 (Jan. 2019), 614-629. https: //doi.org/10.1108/IJSHE-07-2018-0125 Publisher: Emerald Publishing Limited.
[21] Christian Remy, Olivier Bates, Alan Dix, Vanessa Thomas, Mike Hazas, Adrian Friday, and Elaine M. Huang. 2018. Evaluation Beyond Usability | Proceeding of the 2018 CHI Conference on Human Factors in Computing Systems. https: //dl.acm.org/doi/abs/10.1145/3173574.3173790

[22] Christian Remy, Oliver Bates, Vanessa Thomas, and Elaine M. Huang. 2017. The Limits of Evaluating Sustainability. In Proceedings of the 2017 Workshop on Computing Within Limits (LIMITS '17). Association for Computing Machinery, New York, NY, USA, 103-110. https://doi.org/10.1145/3080556.3080567

[23] Tina Ringenson, Elina Eriksson, Miriam Börjesson Rivera, and Josefin Wangel. 2017. The Limits of the Smart Sustainable City. In Proceedings of the 2017 Workshop on Computing Within Limits (LIMITS '17). Association for Computing Machinery, New York, NY, USA, 3-9. https://doi.org/10.1145/3080556.3080559

[24] Andreas Roesch, Serenella Sala, and Niels Jungbluth. 2020. Normalization and weighting: the open challenge in LCA. The International fournal of Life Cycle Assessment 25, 9 (Sept. 2020), 1859-1865. https://doi.org/10.1007/s11367-02001790-0

[25] Six Silberman and Bill Tomlinson. 2010. Toward an ecological sensibility |CHI '10 Extended Abstracts on Human Factors in Computing Systems. In CHI EA '10. 3469-3474. https://doi.org/10.1145/1753846.1754003

[26] Benjamin K. Sovacool. 2019. The precarious political economy of cobalt: Balancing prosperity, poverty, and brutality in artisanal and industrial mining in the Democratic Republic of the Congo. The Extractive Industries and Society 6, 3 (July 2019), 915-939. https://doi.org/10.1016/j.exis.2019.05.018

[27] Will Steffen, Katherine Richardson, Johan Rockström, Sarah E. Cornell, Ingo Fetzer, Elena M. Bennett, Reinette Biggs, Stephen R. Carpenter, Wim de Vries, Cynthia A. de Wit, Carl Folke, Dieter Gerten, Jens Heinke, Georgina M. Mace, Linn M. Persson, Veerabhadran Ramanathan, Belinda Reyers, and Sverker Sörlin. 2015. Planetary boundaries: Guiding human development on a changing planet. Science 347, 6223 (Feb. 2015). https://doi.org/10.1126/science.1259855 Publisher: American Association for the Advancement of Science Section: Research Article.

[28] Örjan Svane. 2013. Energy Efficiency in Hammarby Sjöstad, Stockholm through ICT and smarter infrastructure : survey and potentials. 190-196. http://urn.kb. se/resolve?urn=urn:nbn:se:kth:diva- 124259

[29] Kentaro Toyama. 2015. Preliminary thoughts on a taxonomy of value for sustainable computing. First Monday (July 2015). https://doi.org/10.5210/fm.v20i8.6132

[30] Nicolas Tsurukawa, Siddharth Prakash, and Andreas Manhart. 2011. Social impacts of artisanal cobalt mining in Katanga, Democratic Republic of Congo. Technical Report. Öko-Institut e.V. http://resourcefever.com/publications/reports/ OEKO_2011_cobalt_mining_congo.pdf 